\title{
Effects of ketamine hydrochloride (preservative free) and fentanyl citrate added to low dose hyperbaric bupivacaine for sub-arachnoid block in lower uterine caesarian section - a comperative study
}

\author{
SM Rafiqul Islam ${ }^{*}$, Hasina Begum ${ }^{2}$, Md. Mustafa Kamal ${ }^{3}$, Md. Shah Alam Bhuiyan ${ }^{4}$, UH
} Shahera Khatun ${ }^{5}$

\begin{abstract}
${ }^{1}$ Dept. of Anaesthesiology, Enam Medical College \& Hospital, Savar, Dhaka, ${ }^{2}$ Dept. of Anaesthesiology, Dhaka Dental College \& Hospital, ${ }^{3}$ Dept. of Anaesthesia, Analgesia and Intensive Care Medicin, BSMMU, ${ }^{4}$ Dept. of Anaesthesiolog \& ICU, Burn Unit, Dhaka Medical College Hospital, ${ }^{5}$ Dept. of Anaesthesiology \& ICU, Dhaka Medical College \& Hospital.
\end{abstract}

*Address of correspondence:

\begin{abstract}
Background Caesarian section is one of the most common operations Now a days for delivery of baby sub-arachnoid block is the better choice. World wide Commonly used bupivacaine with fentanile.
\end{abstract}

Objective The present study was designed to observe the effects of intrathecal ketamine hydrochloride with bupivacaine+complne bupivacaine with fentanyl to observe quality of block eioth duration block during caesarian section.

Methods Ninety ASA 1 parturients scheduled for elective caesarian section were randomly selected. There are thirty patients in each group. The base line haemodynamic parameters, heart rate, blood pressure respiratory rate $\mathrm{SpO}_{2}$ and indication of operation were recorded The control group $\mathrm{BN}(n=30)$ received $1.75 \mathrm{ml}$ of $0.5 \%$ hyperbaric bupivacaine plus $0.5 \mathrm{ml}$ normal saline intrathecally. While the study group, fentanyl group $B F(n=30)$ received $1.75 \mathrm{ml}$ of $0.5 \%$ hyperbaric bupivacaine plus $0.5 \mathrm{ml}(25 \mathrm{mg})$ injection fentanyl, BK received $1.75 \mathrm{ml}$ of $0.75 \%$ hyperbaric bupivacaine plus $0.5 \mathrm{ml}$ ( $25 \mathrm{mg}$ ) of ketamine hydrochloride.

Results Duration and quality of sensory and motor block, post-operative analgesia, haemodynamic changes and sedation levels were assessed. There was no significant difference in duration of motor blockade in three groups. Quality of analgesia, sensory block was significant $(P<0.05)$ in BK and BF group than BN group. The quality of block was excellent throughout the surgical procedure in $80 \%$ BK group $60 \%$ in $B F$ group and $53.3 \%$ in control (BN) group. Incidence of hypotension was less in group BF (26.6\%) and BK (20\%) than group BN (40\%). Ketamine had an upper level of sensory block than fentanyl.

Conclusion Injection ketamine $25 \mathrm{mg}$ can be used as an adjunct to low dose spinal bupivacaine during caesarian.

Key words: SAB, Post-operative analgesia, ketamine, fentanyl.

(JBSA 2011; 24(2): 53-59)

\section{Introduction}

Caesarian section is one of the most common operations in the child bearing age of a woman. The choice of anesthetic technique for caesarean section depends on patient preference, coexisting medical conditions, reasons for surgery, the degree of urgency and the anesthesiologist's judgment and experience. Regional anesthesia for caesarean section has become the preferred technique because general anesthesia has been associated with higher maternal mortality. Regional anesthesia is advantageous in terms of less neonatal exposure to potentially depressant drugs, decreased risk of maternal pulmonary aspiration and an awaken mother at the birth of her child ${ }^{1}$. Hyperbaric bupivacaine is the most common 
local anesthetic used in subarachnoid block for caesarean section adding an adjunct (opioids or non opioids) has allowed reduction in the dose of bupivacaine and provides cardiovascular stability ${ }^{2}$. In the context of "augmentation strategies" a wide variety of opioids and non opioids are used as an adjunct to subarachnoid block to improve the quality of anaesthesia and prolongation of analgesia in the post operative period ${ }^{3}$.Opioids added to local anesthetic for subarachnoid block was first introduced into clinical practice in 1979 with morphine sulphate as a forerunner. Morphine is a hydrophilic agent, may not be optimal as intrathecal drug for intraoperative analgesia because of less lipid soluble drug have a slower rate of onset of action and the drug may reach the medulla and cause delayed ventilatory depression ${ }^{4}$. Fentanyl, a lipophilic opioid, has rapid onset of action following intrathecal administration. It does not tend to migrate to fourth ventricle in sufficient concentration to cause delayed respiratory depression ${ }^{5}$. So, fentanyl is suitable as intrathecal drug for intraoperative analgesia and also prolongs analgesia in the early postoperative period ${ }^{6}$. Recently, a non-opioid, NMDA receptor antagonist, ketamine (preservative free) is used for central neuraxial block. Ketamine as an analgesic has gained major attention during last few years because it is the most potent blocker of NMDA receptor's available for clinical use ${ }^{7}$. Epidural route for the administration of ketamine has become popular because of its safety and efficacy ${ }^{8}$.Using the epidural route would give the highest concentration of ketamine at the spinal segments with the minimum systemic effects. Also, the elimination half life of epidural ketamine is longer than that following I.V administration and its CSF concentration is double that in plasma ${ }^{7}$. There are some concerns about the safety of the intrathecal use of ketamine and its preservative, benzal-konium chloride. A recent case report of a terminally ill cancer patient who received a continuous infusion of intrathecal ketamine with preservative for three weeks reported sub-pial vacuolar myelopathy ${ }^{9}$. Preservative-free ketamine has been shown to be devoid of neurotoxic effects after single and repeated administration ${ }^{10,11,12}$. This study was carried out to evaluate and compare the quality of sensory \& motor block between intrathecal ketamine $\mathrm{Hcl}$ and fentanyl with low dose hyperbaric bupivacaine.

\section{Methods}

This study was conducted after obtaining approval from the institutional ethical committee. ASA physical status 1 parturient at term undergoing elective caesarean section willing to be included in the study. History of allergy to these drugs, bleeding diathesis, Pregnancy induced hypertension, COPD, history of taking tricyclic antidepressant drugs were excluded from the study. Patients were randomly selected into three groups by card sampling, 30 in each group. BN, BF \& BK. Group $\mathrm{BN}$ received $0.5 \%$ hyperbaric bupivacaine $1.75 \mathrm{ml}$ $(8.75 \mathrm{mg})+0.5 \mathrm{ml}$ normal saline, group BF received $0.5 \%$ hyperbaric bupivacaine $1.75 \mathrm{ml}(8.75 \mathrm{mg})+$ $0.5 \mathrm{ml}$ Fentanyl (25ug) \& group BK received 0.5\% hyperbaric bupivacaine $1.75 \mathrm{ml}(8.75 \mathrm{mg})+0.5 \mathrm{ml}$ Ketamine (preservative free) $\mathrm{Hcl}(25 \mathrm{mg})$. After taking informed consent from parturient during preoperative visit she was instructed for overnight fasting and Inj. metoclopramide $10 \mathrm{mg}$ intramuscularly 1 hour before operation. In the operating room an intravenous canula of $18 \mathrm{G}$ was inserted and (pre-operative note was taken regarding pulse, blood pressure, heart, lungs, respiratory rate and $\mathrm{SpO}_{2}$ ). Pre-loaded with $15 \mathrm{ml}$ kg- ${ }^{1}$ Ringer's lactate solution. Under all aseptic precaution lumbar puncture was performed with 25 gauge Quincke's spinal needle in $\mathrm{L}_{3-4}$ space in sitting position and study drugs were injected. After noting the time of injection, patient was immediately placed in supine position. A wedge was placed under the right hip. All patients were received supplementation of $\mathrm{O}_{2}$ (3 liter per minute) via facemask. Immediately after administration of spinal anesthesia pulse rate, blood pressure and rate of respiration was recorded. Then Pulse rate, blood pressure, rate of respiration, $\mathrm{SpO}_{2}$ was recorded every 3 minute for first 20 minutes, at 10 minutes interval for remainder of operation and thereafter at 30 minutes interval until the patient complains of pain. The occurrence of discomfort and side effects likes pruritus, nausea or vomiting, shivering, chest pain, restlessness, nystigmus etc. were recorded upto 24 hours. Hypotension defined as a decrease in systolic BP to less than $20 \%$ from the baseline, was treated with bolus of IV Ephedrine 6mg as required. In any patient intensity of pruritus was assessed as mild (itching was only a minor concern), moderate (itching was a primary concern although bearable) or severe (unbearable, 
patient requiring treatments). Sedation was assessed by Ramsay Sedation scale. Incidence of any other discomfort and side effects were also recorded. Height of the sensory block was assessed by pin prick method at 20 minutes after administration of spinal anesthesia. The quality of motor block was assessed by bromage scale. The quality of anesthesia was assessed depending on quality of motor block (onset time, bromage scale) and quality of sensory block (onset time, level of block) and on incidence of side effects, and by interviewing the parturient for their satisfaction, Verbal Rating Scale (VRS). Accordingly quality of anesthesia was categorized as excellent / good / fair / poor. Duration of effective analgesia (time from subarachnoid injection to first dose of rescue analgesic) was recorded as the patients request for first dose of analgesic. APGAR score was recorded at 1 and 5 minute after delivery of the baby.

Mean \pm SD was calculated for the variable at observation time in each group. The data yielded from this study were compiled and analyzed using chi-square $(\chi 2)$ and one way ANOVA test. P value less than 0.05 was considered significant. Analysis was done by using statistical package for social science (SPSS); version 12.0.

\section{Results}

Patients in three groups were homogeneous regarding demographic characteristics.

In Table - I In sensory block, 20\%, 40\%, 33.3\% and $6.7 \%$ of the patients in Group-BN had block at $\mathrm{T}_{5}$, $\mathrm{T}_{6}, \mathrm{~T}_{7}$ and $\mathrm{T}_{8}$ level respectively. In Group- $\mathrm{BF}$
$13.3 \%, 50 \%, 20 \%$ and $16.7 \%$ of the patients had block at $\mathrm{T}_{4}, \mathrm{~T}_{5}, \mathrm{~T}_{6}$ and $\mathrm{T}_{7}$ level respectively. In Group-BK, $26.7 \%, 66.7 \%$ and $6.7 \%$ of the patients had block at $\mathrm{T}_{4}, \mathrm{~T}_{5}$, and $\mathrm{T}_{6}$ level respectively.

Table-I : Sensory block and quality of motor block in three group

\begin{tabular}{|c|c|c|c|c|}
\hline $\begin{array}{l}\text { Param } \\
\text { eters }\end{array}$ & $\begin{array}{l}\text { Group } \\
-\mathrm{BN}\end{array}$ & $\begin{array}{c}\text { Group } \\
-\mathrm{BF}\end{array}$ & $\begin{array}{c}\text { Group } \\
\text {-BK }\end{array}$ & $\begin{array}{c}\mathrm{P} \\
\text { value }\end{array}$ \\
\hline \multicolumn{5}{|c|}{ Level of sensory block at $20 \mathrm{~min}$. } \\
\hline $\begin{array}{l}\mathrm{T}_{4} \\
\mathrm{~T}_{5} \\
\mathrm{~T}_{6} \\
\mathrm{~T}_{7} \\
\mathrm{~T}_{8}\end{array}$ & 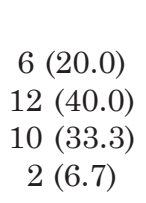 & $\begin{array}{c}4(13.3) \\
15(50.0) \\
6(20.0) \\
5(16.7)\end{array}$ & $\begin{array}{c}8(26.7) \\
20(66.7) \\
2(6.7)\end{array}$ & $9.48 \quad 0.029$ \\
\hline \multicolumn{5}{|c|}{ Quality of motor block (Bromage scale) } \\
\hline Grade-2 & $8(26.7)$ & $8(26.7)$ & $5(16.7)$ & 0.8840 .347 \\
\hline Grade-1 & $22(73.3)$ & $22(73.3)$ & $25(83.3)$ & \\
\hline
\end{tabular}

Regarding quality of motor block, in Group-BN $26.7 \%$ and $73.3 \%$ of the patients had block of grade2 and grade- 1 respectively in Bromage Scale. In Group-BF $26.7 \%$ and $73.3 \%$ patients had block of grade- 2 and grade- 1 respectively. While in GroupBK $16.7 \%$ and 83.3 of the patients had block of grade- 2 and grade- 1 respectively.

Table-II On set time of motor block were $7 \pm 1.80$, $6 \pm 1.11$ and $4 \pm 1.01$ in group $\mathrm{BN}, \mathrm{BF}$ and $\mathrm{BK}$ respectively. The mean on set time of sensory block was $6 \pm 1.01,5 \pm .80$ and $3 \pm .90$ in group BN, $\mathrm{BF}$ and $\mathrm{BK}$ respectively \& there was statistically significant difference in mean on set time of motor block and mean on set time of sensory block among three groups.

Table II : Onset time of motor block and sensory block

\begin{tabular}{lcccllcc}
\hline Parameter & Group-BN & Group-BF & Group-BK & Sources of variation & SS & df & P-value \\
\hline On set time of & $7 \pm 1.80$ & $6 \pm 1.11$ & \multirow{2}{*}{$4 \pm 1.01$} & Between Groups & 126.422 & 2 & $.000^{*}$ \\
motor block & & & & Within Groups & 160.200 & 87 & \\
& & & & Total & 286.622 & 89 & \\
On set time of & \multirow{2}{*}{$6 \pm 1.01$} & \multirow{2}{*}{$5 \pm .80$} & \multirow{2}{*}{$3 \pm .90$} & Between Groups & 64.939 & 2 & $.000^{*}$ \\
sensory block & & & & Within Groups & 71.908 & 87 & \\
\hline
\end{tabular}

$\mathrm{P}<0.05$ is significant.

Table III shows the mean duration of motor and sensory block in three groups. 
Duration of motor block was $98 \pm 10.40,109 \pm 16.42$ and $104 \pm 14.86$ in group $\mathrm{BN}, \mathrm{BF}$ and $\mathrm{BK}$ respectively. The mean duration of sensory block was $111 \pm 14.62,160 \pm 31.85$ and $147 \pm 20.91$ in group $\mathrm{BN}, \mathrm{BF}$ and $\mathrm{BK}$ respectively\& there was statistically significant difference in mean duration of motor block and mean duration of sensory block among three group

Table IV shows duration of motor and sensory block in $\mathrm{BF}$ and $\mathrm{BK}$ groups.

Pruritus (46.7\%) was the only side effect observed in patients belonging to Group-BF.

The incidence of Nystigmus \& strange feeling was $20 \% \& 10 \%$ of the patients in Group BK only.

In Table IV shown quality of anesthesia was categorized as excellent, good, fair and poor depending on quality of motor and sensory block, per-operative anesthesia and parturient satisfaction on verbal rating scale (VRS) and also on the incidence of side effects. In Group-BN 53.3\% had excellent anesthesia, $30 \%$ and $16.7 \%$ of the patients had good and fair scale of anesthesia respectively. In Group-BF $60 \%$ of the patients had excellent and $40 \%$ of the patients had good scale of anesthesia. In Group-BK $80 \%$ of patients had excellent scale of anesthesia and $20 \%$ of the patients had good scale of anesthesia.

Quality of anesthesia in two groups- BF and BK was statistically insignificant $(\mathrm{P}=0.091)$.

Table V shows that the V.R. of duration of effective Analgesia $(\mathrm{P}=0.000)$ is greater than the critical value of $\mathrm{F}_{0.05,2,87}(3.10)$, then it may be concluded that the mean duration of effective analgesia compared in three groups had statistically significant difference.

Table III

Duration of motor block and sensory block

\begin{tabular}{llllllll}
\hline Parameter & Group-BN & Group-BF & Group-BK & Sources of variation & SS & df & P-value \\
\hline Duration of & $98 \pm 10.40$ & $109 \pm 16.42$ & $104 \pm 14.86$ & Between Groups & 1927.222 & 2 & $0.010^{*}$ \\
motor block & & & & Within Groups & 17364.167 & 87 & \\
& & & & Total & 19291.389 & 89 & \\
Duration of & \multirow{2}{*}{$111 \pm 14.62$} & $160 \pm 31.85$ & \multirow{2}{*}{$147 \pm 20.91$} & Between Groups & 38301.667 & 2 & $0.000^{*}$ \\
sensory block & & & & Within Groups & 48300.833 & 87 & \\
\hline & & & & Total & 86602.500 & 89 \\
\hline
\end{tabular}

Data were expressed as mean $\pm \mathrm{SD}, \mathrm{p}<0.05=$ significant, ${ }^{*}=$ significant.

Table IV

Quality of Anesthesia in three groups

\begin{tabular}{lccccr}
\hline Parameters & Group-BN & Group-BF & Group-BK & c $^{2}$ value & P value \\
\hline Excellent & $16(53.3)$ & $18(60.0)$ & $24(80.0)$ & 2.857 & 0.091 \\
Good & $9(30.0)$ & $12(40.0)$ & $6(20.0)$ & & \\
Fair & $5(16.7)$ & 0 & 0 & & \\
\hline
\end{tabular}


Table V : APGAR score in three groups:

\begin{tabular}{lccccc}
\hline APGAR & Group-BN & Group-BF & Group-BK & $\chi^{2}$ value & P value \\
\hline After 1 minute & & & & & \\
7 & $1(3.3)$ & & & & \\
8 & $8(26.7)$ & $8(26.7)$ & $7(23.3)$ & 2.843 & 0.828 \\
9 & $5(16.7)$ & $7(23.3)$ & $5(16.7)$ & & \\
10 & $16(53.3)$ & $15(50.0)$ & $18(60.0)$ & & \\
After 5 minute & & & & & \\
8 & $1(3.3)$ & 0 & 0 & 2.225 & 0.694 \\
9 & $3(10.0)$ & $4(13.3)$ & $3(10.0)$ & & \\
10 & $26(86.7)$ & $26(86.7)$ & $27(90.0)$ & & \\
\hline
\end{tabular}

Comparison among three groups had statistically insignificant difference in APGAR Score at 1 minute $(\mathrm{P}=0.828)$ after delivery and at 5 minutes $(\mathrm{P}=0.694)$ after delivery.

Table VI : Duration of effective Analgesia

\begin{tabular}{lccccc}
\hline Sources & SS & df & MS & V.R. & P-value \\
\hline Between Groups & 45743.901 & 2 & 22871.950 & 44.027 & $0.000^{*}$ \\
Within Groups & 44676.908 & 86 & 519.499 & & \\
\hline Total & 90420.809 & 88 & & & \\
\hline
\end{tabular}

Table VII : Incidence of hypotension in three groups

\begin{tabular}{lcccc}
\hline Parameters & Group-BN $(\mathrm{n}=30)$ & Group-BF $(\mathrm{n}=30)$ & Group-BK $(\mathrm{n}=30)$ & P value \\
\hline Ephedrine given & $12(40.0)$ & $8(26.7)$ & $6(20.0)$ & 0.220 \\
\hline
\end{tabular}

Data are presented as frequencies. Values within parentheses are expressed as percentage over column total.

Figure 1 shows that the changes in pulse rate of group BK was lower than that of group BN and group BF. It also shows that the gap of pulse rate was high among the three groups after $90 \mathrm{~min}$. of per operative period (group BK was max. and group $\mathrm{BF}$ was min.), though the gap was comparatively low in the baseline period.

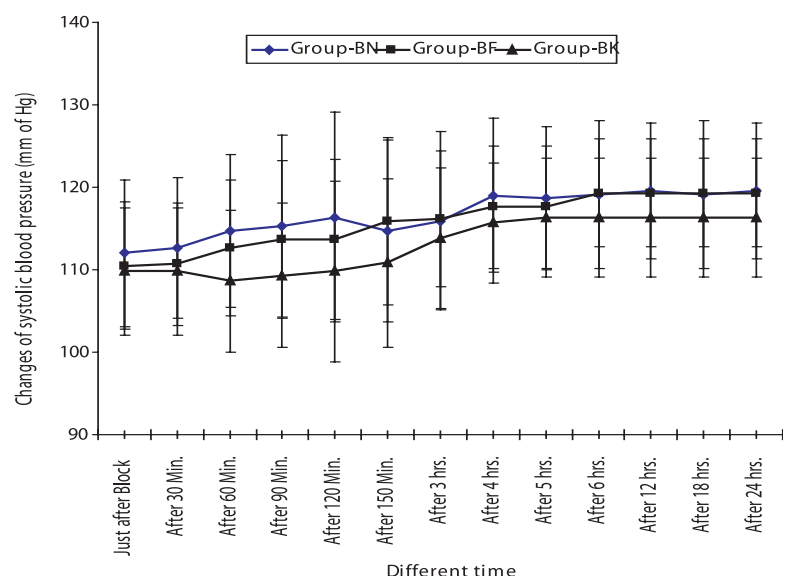

Fig 2 Changes of systolic blood pressure $(\mathrm{mm} \mathrm{Hg})$ (per operative)
Figure 2 shows that the changes of systolic blood pressure of group BK was lower than that of group $\mathrm{BN}$ and group BF after $90 \mathrm{~min}$. of per operative period (group BK was max. and group BF was min.).

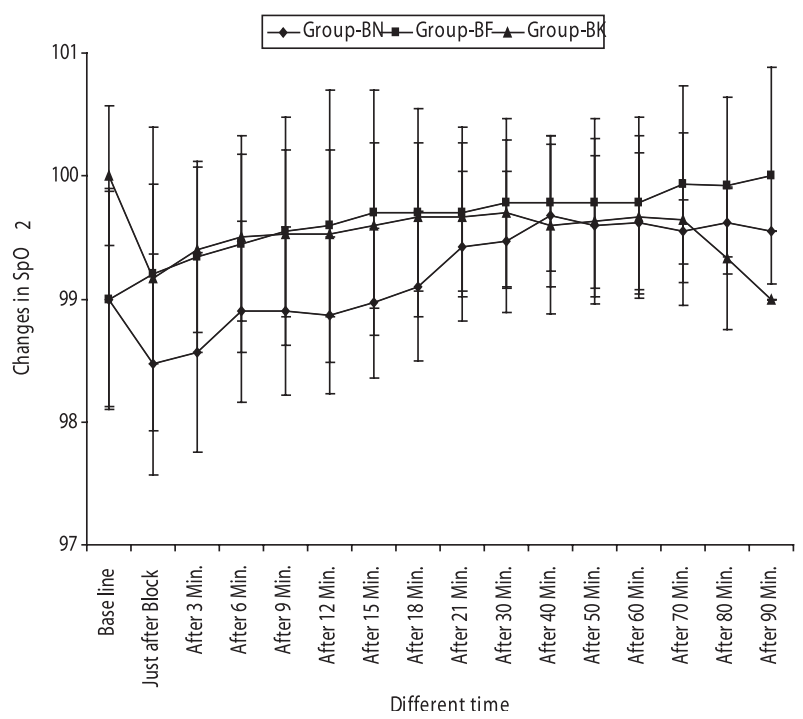

Fig- 2: Changes in $\mathrm{SpO}_{2}$ (per operative) 
Figure 3 shows that the changes in $\mathrm{SpO}_{2}$ of group $\mathrm{BK}$ was lower than that of group $\mathrm{BN}$ and group $\mathrm{BF}$ after 90 min. period, though the $\mathrm{SpO}_{2}$ was comparatively high in the baseline period.

Incidence of post operative side effects: pruritus (43.3\%) was the only side effect observed in patients belonging to Group-BF. Incidence of nausea was $16.7 \%$ in Group BF only. Incidence of vomiting was also $3.3 \%$ in Group BF only. Dizziness was observed in $20 \%$ of the patients only in Group BN. Incidence of strange feeling was 13\% in Group BK only. Incidence of shivering was $20 \%$ and $16.6 \%$ in Group BN and BF respectively.

\section{Discussion}

In the present study, patients were randomly allocated in three groups-BN, BF and BK, in group $\mathrm{BN} 0.5 \mathrm{ml}$ normal saline $+1.75 \mathrm{ml} 0.5 \%$ hyperbaric bupivacaine, in group BF $0.5 \mathrm{ml}$ (25ìg) fentanyl + $1.75 \mathrm{ml} 0.5 \%$ hyperbaric bupivacaine, and in group BK $0.5 \mathrm{ml}(25 \mathrm{mg})$ ketamine (preservative free) + $1.75 \mathrm{ml} \mathrm{0.5 \%} \mathrm{hyperbaric} \mathrm{bupivacaine} \mathrm{were} \mathrm{used}$ for induction of subarachnoid block. Final height of the block was assessed by pin prick in $20 \mathrm{~min}$. after block, because bupivacaine fixed at this time and no further progression of the block occurred.

In BK group $26.7 \%$ patients had sensory block at $\mathrm{T}_{4}$ and in $\mathrm{BF}$ group 13.3\% patients had sensory block at $\mathrm{T}_{4}$ while in $\mathrm{BN}$ group (Control) no patients had sensory block at $\mathrm{T}_{4}$ level. So, ketamine (preservative free) and fentanyl had higher level of sensory block than control group which was statistically significant $(\mathrm{P}=.000)$. Again ketamine (preservative free) group had higher level of sensory block than fentanyl group which was statistically significant $(\mathrm{P}=.029)$. There was no statistically significant difference $(\mathrm{P}=0.347)$ in assessment motor block among three groups observed by bromage Scale. This result is consistent in terms of level of sensory block with the study conducted by Kathirvel et al ${ }^{13}$ and Biswash et al. ${ }^{6}$.

Cardiovascular effect of spinal block was measured in terms of number of patients developed hypotension and required treatment with Inj. ephedrine. Hypotension was defined as reduction systolic blood pressure to $20 \%$ or more than the base line. In group BK 20\% and in group BF 26.7\% while $40 \%$ of patients in group BN developed hypotension. The incidence of hypotension among three groups was statistically insignificant $(\mathrm{P}=$ 0.220). In BK \& BF group, though dose of the bupivacaine was not reduced, cardiovascular stability in respect of hypotension was found insignificant.

There have been reports of respiratory depression when intrathecal lipophilic opioid has been used for labour analgesia byLu et al. ${ }^{14}$ \& Hays \& Pabner ${ }^{15}$. But during caesarean delivery significant respiratory depression has not been observed by Dahlgren et al. ${ }^{16}$ \& Hunt et al ${ }^{17}$. Intrathecal ketamine (preservative free) didn't induce respiratory depression reported by Kathirvel \& Shadasivam ${ }^{13}$ even after massive dose of 250 mg Mankowitz et al. ${ }^{18}$. In our study no patient in any groups experienced respiratory depression.

The incidence of discomfort and side effects observed during the study was less in BK \& BF groups than BN group (Control Group).

Quality of anesthesia was categorized as excellent, good, fair and poor depending on assessment of motor block, level of sensory block and the incidence of side effects. Quality of anesthesia was better in $\mathrm{BF} \& \mathrm{BK}$ than control group $\mathrm{BN}$ which was statistically significant $(\mathrm{P}=0.008)$. On the other hand BK group had better quality of anesthesia than group BF which was statistically insignificant $(\mathrm{P}=0.091)$.

Neonatal APGAR score was similar among three groups.

Mean duration of effective analgesia in group BN, BF \& BK were $128 \pm 13.78,181 \pm 30.17$ and $169 \pm$ 21.14 minute respectively which was statistically highly significant $(\mathrm{P}=0.000)$. On the other hand, there were small difference in postoperative analgesia in group BF \& BK which was not statistically significant $(\mathrm{P}=0.072)$.

There were two important observations in the study. One was in BK group there was no nausea and vomiting in peroperative and postoperative period. And another observation was that there was less incidence of hypotension in BF and BK group than BN group with same dose of bupivacaine. These two observations may be further evaluated.

Limitation of this study is that only one dose of ketamine (preservative free) was used. Dose- 
response study was not carried out because previous study has already shown that ketamine (preservative free) dose-dependency potentiates the local anesthetic effect. Similar dose response relationship in study where 20,40 or 60 ig of fentanyl was administered and prolongation of effect was found in higher doses but with increased pruritus reported by Belzrena et al. ${ }^{21}$ Sample size was also small in this study.

Concluded that subarachnoid ketamine ( $25 \mathrm{mg}$ ) with low dose hyperbaric bupivacaine is an alternative to subarachnoid fentanyl with low dose hyperbaric bupivacaine for elective caesarean section in terms of quality of block, haemodynamic stability, incidence of side effects, quality of anesthesia, duration of post operative analgesia and foetal outcome.

\section{References:}

1. Morgan EG, Mikhali MS, Murray MJ. Maternal and foetal physiology anaesthesia. In: clinical anaesthesiology, $3^{\text {rd }}$ edition, New York: Mc Grow-Hill, 2002; 805

2. Dyer RA, Joubert A, Ivan A. Low-dose spinal anesthesia for Cesarean section. Anesthesiology 2004; 4: 303-308

3. Saxena, AK, Arava, SK. Current concepts in Neuraxial Administration of opioids and nonopioids: an overview and Future Perspective, Indian J. Anaesth 2004; 48:13-24

4. Alan, RA, David J, Rowbotham, Smith G, 'Postoperative pain', Textbook of anaesthesia, $4^{\text {th }}$ edition, Churchill Livingstone 544-554

5. Etches, RC, Sandler, AN, Daley, MD. Respiratory depression and spinal opioids. Can J. Anaesth 1989; 36:165-85

6. Biswas, BN, Rudra, A, Bose, BK, et al. Intrathecal fentanyl with hyperbaric bupivacaine improves analgesia during caesarean delivery and in early post-operative period. Indian J. Anaesth. 2002; 46: 469-472

7. Ghaffar, AME, Abdulatif $\mathrm{M}$ et al. Epidural ketamine reduces post- operative epidural PCA consumption of fentanyl/bupivacaine. Can J. Anesthesia 1998; 45: 103-109

8. Nagubm, Abu-Gyamfi, Y, Absood, GH, Faragh, Gyasi, HK, Epidural ketamine for postoperative analgesia. Can J. Anesthesia 1986; 33: 16-21

9. Karpinski, N, Hansen, DJL, Masliah E. Subpial vacuolar myelopathy after intrathecal ketamine: report of a case. Pain 1997; 73: 103-5

10. Borgbjerg, FM, Svensson, BA, Frigast C, Gordh T. Histopathology after repeated intrathecal injections of preservative-free ketamine in the rabit: a light and electron microscopic examination. Anesthesia and Analgesia 1994; 79: 105-11

11. Malinovski JM, Lepage JY, Cozain A, et al. Is ketamine or its preservative responsible for neurotoxicity in the rabbit? Anesthesiology 1993; 78: 109-15

12. Brock-Unte JG, Mankowitz E, Kallichurum S, Dowing JW. Effects of intrathecal saline and ketamine with and without preservative on the spinal roots of monkey. South African Medical Journal 1982; 61: 360-61

13. Kathirvel S, Shadasivam SA, Saxena, et al. Effects of intrathecal Ketamine added to bupivacaine for spinal anesthesia. Anesthesia 2000; 55: 899-910

14. Lu JK, Schafer PG, Gurdner TL, et al. The dose response pharmacology of intrathecal sufentanil in female volunteers. Anesth analg 1997; 85: 372-79

15. Hays RL, Pabner GM. Respiratory depression after intrathecal sufentanil during labour. Anesthesioloy 1994; 79: 1288-93

16. Dahlgren G, Hultsrand C. Intrahecal sufentanil, fentanyl or placebo added to bupivacaine for caesarean section. Obstet Anesth 1997; 85: 1288-1293

17. Hunt CO, Namitry JS, Bader AM, et al. Peroperative analgesia with subarachnoid fentanyl bupivacaine for caesarean delivery. Anesthesiology 1989; 71: 535-40

18. Mankowitz E, Brock-Unte JG, Connet, JE, Thompson, GR, et al. Epidural ketamine, A preliminary report. South African Med J, 1982; 61: 441-2.

19. Bader AM, Thormill M, Datta S. The antiematic efficacy and safety of prohylacitc metoctopramide for elective caesarean delivery during spinal anaesthesia. Reg Anaesth 1992; 17: $126-30$

20. Eisenach JC, DeKock M, Klimscha W. Alpha (2) adrenergic agonists for regional anesthesia. A clinical review of clonidine Anesthesiology 1996; 85: 655-74.

21. Belzrena SD. Clinical effects of intrathecally administered fentanyl in patients undergoing caesarean section. Anesth analg 1992; 74: 653-657 